\title{
Seroprevalence of Toxoplasma gondii in Cats from Cyprus
}

\author{
Charalampos Attipa ${ }^{1,2,3, *(\mathbb{D})}$, Christos Yiapanis ${ }^{3}$, Séverine Tasker ${ }^{4,5}$ (D) and Anastasia Diakou ${ }^{6, *(D)}$ \\ 1 Department of Tropical Disease Biology, Liverpool School of Tropical Medicine, Liverpool L3 5QA, UK \\ 2 Malawi Liverpool Wellcome Trust Clinical Research Programme, Blantyre, Malawi \\ 3 Cyvets Veterinary Center, Paphos 8025, Cyprus; drcy@cyvets.com \\ 4 Bristol Veterinary School, University of Bristol, Bristol BS40 5DU, UK; S.Tasker@bristol.ac.uk \\ 5 Linnaeus Group, Shirley, Solihull B90 4BN, UK \\ 6 Faculty of Health Sciences, School of Veterinary Medicine, Aristotle University of Thessaloniki, \\ Thessaloniki 54124, Greece \\ * Correspondence: attipacy@gmail.com or charalampos.attipa@lstmed.ac.uk (C.A.); diakou@vet.auth.gr (A.D.)
}

Citation: Attipa, C.; Yiapanis, C.;

Tasker, S.; Diakou, A. Seroprevalence of Toxoplasma gondii in Cats from Cyprus. Pathogens 2021, 10, 882. https://doi.org/10.3390/ pathogens 10070882

Academic Editor: Valentina

Virginia Ebani

Received: 27 May 2021

Accepted: 9 July 2021

Published: 12 July 2021

Publisher's Note: MDPI stays neutral with regard to jurisdictional claims in published maps and institutional affiliations.

Copyright: (c) 2021 by the authors. Licensee MDPI, Basel, Switzerland. This article is an open access article distributed under the terms and conditions of the Creative Commons Attribution (CC BY) license (https:/ / creativecommons.org/licenses/by/ $4.0 /)$.

\begin{abstract}
Toxoplasma gondii is a cosmopolitan protozoon parasite, and the causative agent of toxoplasmosis, one of the most prevalent zoonotic parasitic diseases. Cats, as definitive hosts, spread the parasite via their faeces, but this occurs only for a very short period in their life. Seropositivity in cats, although not associated with current shedding of the parasite, is indicative of the infection in a cat population and can be used to assess the infection risk for definitive and intermediate hosts in that area. In order to assess the prevalence of infection in cats living in Cyprus, 155 cats, originating from all districts of the country, were examined for the presence of T. gondii antibodies. Additionally, parameters such as age, sex, health status, lifestyle and concomitant infections were statistically assessed as potential risk factors for $T$. gondii seropositivity. Specific anti- $T$. gondii antibodies were detected in 50 (32.3\%) cats, while the presence of feline immunodeficiency virus antibodies and a history of never having been vaccinated were statistically associated with $T$. gondii seropositivity on multivariate logistic regression analysis. This is the first report of $T$. gondii seroprevalence in cats in Cyprus and indicates that raised public awareness should be considered to prevent infection of animals and humans.
\end{abstract}

Keywords: Cyprus; domestic cat; seroprevalence; Toxoplasma gondii

\section{Introduction}

The apicomplexan protozoon Toxoplasma gondii is one of the most extensively studied zoonotic parasites. It has a heteroxenous lifecycle that was fully described in 1970, when several different groups of investigators identified the domestic cat (Felis catus) as the definitive host [1]. The parasite passes its sexual, enteroepithelial phase in felids, and spreads into the environment in the form of environmentally resistant oocysts, shed through the faeces of infected felids. Sporulated oocysts, which develop from immature oocysts a few days after their excretion in cat faeces, are the infective stage for intermediate hosts, which comprise virtually all warm-blooded animals and humans [2,3]. Generally, both definitive and intermediate hosts may be infected (a) horizontally, by ingesting sporozoites in sporulated oocysts from the environment or by consuming bradyzoites and/or tachyzoites in tissue cysts in infected intermediate hosts, and (b) vertically, by transplacentally (or/and lactogenically in some species, e.g., goats, cats) transmitted tachyzoites [3,4].

Toxoplasma gondii infection usually remains subclinical in cats, although vertical toxoplasmosis or infection in immunocompromised cats may cause severe disease and even death [5]. Conversely, toxoplasmosis is considered one of the most important causes of abortion and, thus, of economic losses in livestock, particularly sheep and goat farming. Furthermore, toxoplasmosis has important zoonotic implications and infects, by estimation, nearly one third of the global human population [6], as one of the main foodborne diseases causing death [7]. 
At any given time, approximately $0.1-1 \%$ of cats are expected to shed oocysts, based on the observation that most cats only shed oocysts for about 1-2 weeks in their life [8,9]. However, in this short period of time, a cat can excrete millions of oocysts, which can remain infective in the environment for months and infect many hosts [10]. Diagnosis of infection in cats can be attempted by copromicroscopic examination; however this is not a helpful approach as (i) the enteroepithelial phase is very short, and (ii) other oocysts with indiscriminate morphology, i.e., species of the genera Hammondia and Besnoitia, can occur in cat faeces, necessitating molecular identification of the parasite [9].

Cats seroconvert approximately 1-2 weeks after the end of the enteroepithelial phase; thus, a seropositive cat no longer sheds oocysts [11]. Although seropositivity for T. gondii antibodies does not indicate that the cat is currently shedding the parasite, and not all seropositive cats have shed oocysts in the past [12,13], seroepizootiological studies are a useful indicative of infection in an area and a given cat population, and can be used to assess the infection risk for definitive and intermediate hosts in that same area [14].

Seroprevalance for T. gondii in domestic cats is estimated to be between 30 and 40\%, worldwide [1]; however, depending on geography and sample size, seroprevalence has varied between $4.8 \%$ and $100.0 \%$ [5]. Although several reports on seroprevalence in cats have been published, there is still a paucity of information in many regions and countries of the world. The Republic of Cyprus is an islandic state in the eastern Mediterranean Sea, with a large number of cats, both pets and free-roaming or stray, that are often infected with multiple pathogens [15-17]. In this country, a limited number of surveys investigating the prevalence of $T$. gondii infection in humans and intermediate hosts have been reported $[18,19]$. However, the prevalence of infection in cats has never been investigated. In this context, the aim of the present study was to investigate the seroprevalence of T. gondi infection in cats from Cyprus, and to explore possible risk factors associated with seropositivity in cats. We report a seroprevalence of $32.3 \%$ of anti-T. gondii IgG in this population of cats and that a lack of vaccination and the presence of feline immunodeficiency virus (FIV) antibodies were associated with $T$. gondii seropositivity.

\section{Materials and Methods}

\subsection{Study Design, Site Populations and Sampling}

Blood samples of cats, both healthy and clinically ill, living in all six districts of Cyprus, i.e., Famagusta, Kyrenia, Larnaca, Limassol, Nicosia and Paphos, were collected in veterinary clinics from March to September 2014 as part of a previous study [17]. The samples were collected by the attending veterinarians during clinical routine examinations for healthy cats or medical checks for ill cats. Aliquots of 155 serum samples were used in the present study with the informed written consent of cat owners or animal shelter managers. For every cat, data concerning district of origin, habitat (rural or urban), age ( $\leq 1$ year or $>1$ year, on the basis of health records), sex, breed, housing (access to outdoors or indoors only living), lifestyle (sheltered-stray or owned cat), previous travel history outside Cyprus, health status and vaccination status, use of ectoparasitic prevention and presence of anaemia (haematocrit $<25 \%$ ) based on in-house complete blood count were recorded. The serum samples were stored at $-80^{\circ} \mathrm{C}$ until they were transferred to the Laboratory of Parasitology and Parasitic Diseases, School of Veterinary Medicine, Aristotle University of Thessaloniki, Greece for examination.

\subsection{Serological Examination}

The serum samples were examined with the commercial kit ID Screen ${ }^{\circledR}$ Toxoplasmosis Indirect Multi-species ELISA (ID.vet, Grabels, France), which detects anti-T. gondii IgG antibodies. The kit, which uses a purified peptide of the main P30 T. gondii protein as a substrate and a multi-species peroxidase (po) as conjugates, has shown a high level of concordance with other serological tests, and has been proved useful for toxoplasmosis serological screening in cats [20]. The test was performed following the manufacturer's instructions. Briefly, for each sample, the sample to positive ratio ( $/ \mathrm{p} \%$ ) was calculated 
taking the optical density (OD) of the positive control (pc) and negative control (nc) into account, as follows:

$$
\frac{\mathrm{s}}{\mathrm{p}} \%=\frac{\mathrm{ODs}-\mathrm{ODnc}}{\mathrm{ODpc}-\mathrm{ODnc}} \times 100
$$

Samples with an $\mathrm{s} / \mathrm{p} \% \leq 40 \%$ were considered negative, between $40 \%$ and $50 \%$ were considered doubtful and $\geq 50 \%$ were considered positive.

Additionally, in the framework of a previously published study [17], all samples underwent retroviral serology testing using PetCheck FeLV Antigen Test and PetCheck FIV Antibody Test (IDEXX Laboratories, Westbrook, ME, USA), Leishmania infantum antibody testing as well as PCR for Bartonella henselae, "Candidatus Mycoplasma haemominutum" (CMhm), "Candidatus Mycoplasma turicensis" (CMt) Ehrlichia/Anaplasma spp., Hepatozoon spp., Leishmania spp., and Mycoplasma haemofelis (Mhf).

\subsection{Data Analysis}

Univariate analysis was performed to evaluate for associations between seropositivity for T. gondii and demographic characteristics, as well as multiple co-infecting pathogens. Pearson's Chi-square test was performed for the categorical variables. Variables with a trend towards significant association with $T$. gondii seropositivity ( $p$-value $<0.2)$ were selected for further analysis with multivariate logistic regression. For the final model, a backward selection was used, and once a final model was structured, all the previously excluded variables were then individually retested and, if then significant, were included in the final model. For both the univariate and multivariate models, a $p$-value $\leq 0.05$ was considered statistically significant. Statistical analysis was performed using SPSS for Windows (version 25.0; SPSS Inc., Chicago, IL, USA).

\section{Results}

Of the 155 examined samples, 50 (32.3\%) were positive for T. gondii antibodies, with the remainder yielding negative results. At a district level, the percentage of seropositive cats was in Paphos 33.0\%, Limassol 24.0\%, Nicosia 36; 0\%, Larnaca 31.0\%, Kyrenia 40.0\%, and Famagusta $29.0 \%$ (Figure 1). The age of seropositive cats ranged from 0.7 to 22.0 years (median 5.1 years, interquartile range 8 years), with 81 (52.3\%) being male and $143(92.3 \%)$ being non-pedigree cats. Tables 1 and 2 show the demographic characteristics of this feline population, as well as the seroprevalence of $T$. gondii among the multiple co-infecting pathogens. The entire data set can be found in Supplementary File 1.

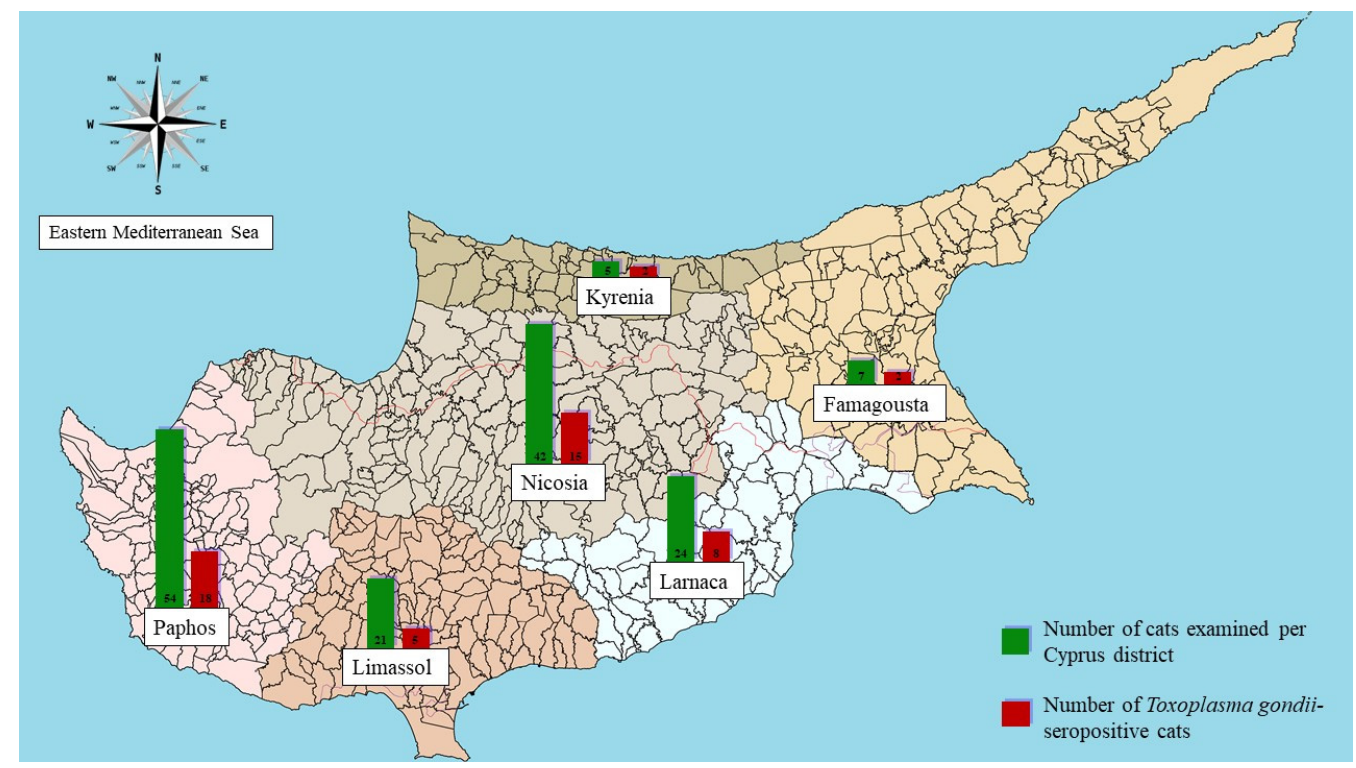

Figure 1. Toxoplasma gondii seropositivity in cats from the different districts of Cyprus. 
Table 1. Comparison of Toxoplasma gondii seropositivity and univariable analysis in cats from Cyprus per non-infectious categorical variable.

\begin{tabular}{|c|c|c|c|}
\hline \multirow{2}{*}{ Variable (No. of Records) } & \multirow{2}{*}{ No. of Cats (\%) } & \multicolumn{2}{|c|}{ T. gondii Seropositive Cats } \\
\hline & & No. $(\% \pm 95 \% \mathrm{CI})$ & $p$-Values \\
\hline \multicolumn{4}{|l|}{ Age (155) } \\
\hline$\leq 1$ year & $17(11.0)$ & $3(17.6 \pm 18.1)$ & 0.172 \\
\hline$>1$ year (Ref.) & $138(89.0)$ & $47(34.1 \pm 7.9)$ & \\
\hline \multicolumn{4}{|l|}{ Gender (155) } \\
\hline Male & $81(52.3)$ & $25(30.9 \pm 10.0)$ & 0.698 \\
\hline Female (Ref.) & $74(47.7)$ & $26(33.8 \pm 10.7)$ & \\
\hline \multicolumn{4}{|l|}{ Breed (155) } \\
\hline Non-Pedigree & $143(92.3)$ & $49(34.3 \pm 7.7)$ & 0.065 \\
\hline Pedigree (Ref.) & $12(7.7)$ & $1(8.3 \pm 15.6)$ & \\
\hline \multicolumn{4}{|l|}{ Housing (155) } \\
\hline Access to outdoors & $119(76.8)$ & $43(36.1 \pm 12.9)$ & 0.061 \\
\hline Indoors only (Ref.) & $36(23.2)$ & $7(19.4 \pm 12.9)$ & \\
\hline \multicolumn{4}{|l|}{ Lifestyle (155) } \\
\hline Shelter-feral & $32(20.6)$ & $13(40.6 \pm 17.0)$ & 0.256 \\
\hline Owned (Ref.) & $123(79.4)$ & $37(30.1 \pm 8.1)$ & \\
\hline \multicolumn{4}{|l|}{ District (155) } \\
\hline Paphos (Ref.) & $54(34.8)$ & $18(33.3 \pm 12.6)$ & 0.280 \\
\hline Nicosia & $42(27.1)$ & $15(35.7 \pm 14.5)$ & \\
\hline Larnaca & $26(16.8)$ & $8(30.8 \pm 17.7)$ & \\
\hline Limassol & $21(13.5)$ & $5(23.8 \pm 18.2)$ & \\
\hline Famagousta & $7(5.0)$ & $2(28.6 \pm 33.5)$ & \\
\hline Kyrenia & $5(3.2)$ & $2(40.0 \pm 42.9)$ & \\
\hline \multicolumn{4}{|l|}{ Habitat (155) } \\
\hline Rural & $59(38.1)$ & $23(39.0 \pm 12.4)$ & 0.160 \\
\hline Urban (Ref.) & $96(61.9)$ & $27(28.1 \pm 8.9)$ & \\
\hline \multicolumn{4}{|l|}{ Travel history (155) } \\
\hline Never travelled abroad & $141(91.0)$ & $45(31.9 \pm 7.7)$ & 0.772 \\
\hline Travelled abroad (Ref.) & $14(9.0)$ & $5(35.7 \pm 25.0)$ & \\
\hline \multicolumn{4}{|l|}{ Health status (155) } \\
\hline Non-healthy & $115(74.2)$ & $39(33.9 \pm 8.6)$ & 0.455 \\
\hline Healthy (Ref.) & $40(25.8)$ & $11(27.5 \pm 13.8)$ & \\
\hline \multicolumn{4}{|l|}{ Vaccination status (146) } \\
\hline Never vaccinated & $41(28.1)$ & $19(46.3 \pm 15.2)$ & 0.016 \\
\hline Vaccinated (Ref.) & $105(71.9)$ & $27(25.7 \pm 8.3)$ & \\
\hline \multicolumn{4}{|l|}{ Ectoparasite prevention (146) } \\
\hline Never applied & $56(38.4)$ & $24(42.9 \pm 12.9)$ & 0.020 \\
\hline Applied (Ref.) & $90(61.6)$ & $22(22.4 \pm 8.6)$ & \\
\hline \multicolumn{4}{|l|}{ Haematocrit (118) } \\
\hline Anaemic & $28(23.7)$ & $11(39.3 \pm 18.0)$ & 0.358 \\
\hline Non-anaemic & $90(76.3)$ & $27(30.0 \pm 9.5)$ & \\
\hline
\end{tabular}

$\overline{p \text {-values }<0.2 \text { but }>0.05 \text { are shown in italics. Significant } p \text {-values } \leq 0.05 \text { are shown in bold; CL: Confidence }}$ interval; Ref: Reference category. 
Table 2. Comparison of Toxoplasma gondii seropositivity and univariable analysis in cats from Cyprus with different co-infective agents.

\begin{tabular}{|c|c|c|c|}
\hline \multirow{2}{*}{ Variable (No. of Records) } & \multirow{2}{*}{ No. of Cats (\%) } & \multicolumn{2}{|c|}{ T. gondii Seropositive Cats } \\
\hline & & No. $(\% \pm 95 \% \mathrm{CI})$ & $p$-Values \\
\hline \multicolumn{4}{|l|}{ FeLV antigen (152) } \\
\hline Positive & $9(5.9)$ & $1(11.1 \pm 20.5)$ & 0.152 \\
\hline Negative (Ref.) & $143(94.1)$ & $49(34.3 \pm 7.8)$ & \\
\hline \multicolumn{4}{|l|}{ FIV antibody (152) } \\
\hline Positive & $27(17.8)$ & $18(66.7 \pm 17.7)$ & $<0.0001$ \\
\hline Negative (Ref.) & $125(82.2)$ & $32(25.6 \pm 7.6)$ & \\
\hline \multicolumn{4}{|l|}{ Any haemoplasma PCR (155) } \\
\hline Positive & $39(25.2)$ & $16(41.0 \pm 15.4)$ & 0.678 \\
\hline Negative (Ref.) & $116(73.8)$ & $34(29.3 \pm 8.3)$ & \\
\hline \multicolumn{4}{|l|}{ Mhf PCR (155) } \\
\hline Positive & $10(6.5)$ & $4(40.0 \pm 30.4)$ & 0.588 \\
\hline Negative (Ref.) & 145 (93.5) & $46(31.7 \pm 7.6)$ & \\
\hline \multicolumn{4}{|l|}{ CMhm PCR (155) } \\
\hline Positive & $31(20.0)$ & $14(45.2 \pm 17.5)$ & 0.086 \\
\hline Negative (Ref.) & $124(80.0)$ & $36(29.0 \pm 7.9)$ & \\
\hline \multicolumn{4}{|l|}{ CMt PCR (155) } \\
\hline Positive & $9(5.8)$ & $3(33.3 \pm 30.8)$ & 0.943 \\
\hline Negative (Ref.) & $146(94.2)$ & $47(32.2 \pm 7.6)$ & \\
\hline \multicolumn{4}{|l|}{ Any FVBP PCR (155) } \\
\hline Positive & $73(47.1)$ & $29(39.7 \pm 11.2)$ & 0.061 \\
\hline Negative (Ref.) & $82(52.9)$ & $21(25.6 \pm 9.4)$ & \\
\hline \multicolumn{4}{|l|}{ L. infantum infection * (155) } \\
\hline Positive & $12(7.7)$ & $3(25.0 \pm 24.5)$ & 0.576 \\
\hline Negative (Ref.) & $143(92.3)$ & $47(32.9 \pm 7.7)$ & \\
\hline \multicolumn{4}{|l|}{ B. henselae PCR (155) } \\
\hline Positive & $16(10.3)$ & $7(43.8 \pm 24.3)$ & 0.576 \\
\hline Negative (Ref.) & $139(89.7)$ & $43(30.9 \pm 7.7)$ & \\
\hline \multicolumn{4}{|l|}{ Hepatozoon spp. PCR (155) } \\
\hline Positive & $62(40.0)$ & $26(41.9 \pm 12.3)$ & 0.035 \\
\hline Negative (Ref.) & $93(60.0)$ & $24(25.8 \pm 8.9)$ & \\
\hline \multicolumn{4}{|c|}{$\begin{array}{l}\text {-values }<0.2 \text { but }>0.05 \text { are shown in italics. Significant } p \text {-values } \leq 0.05 \text { are shown in bold; Any haemoplasma } \\
\text { PCR: Positivity in at least one of the following haemoplasma PCRs: Mhf, CMhm and CMt; CI: Confidence interval } \\
\text { CMhm: "Candidatus Mycoplasma haemominutum"; CMt: "Candidatus Mycoplasma turicensis"; FeLV: feline } \\
\text { leukaemia virus; FIV: feline immunodeficiency virus; FVBP: Feline Vector Borne Pathogen-positive for at leas } \\
\text { one of the PCRs for B. henselae, Ehrlichia / Anaplasma spp. and/or Hepatozoon spp., and/or L. infantum infection } \\
\text { Mhf: Mycoplasma haemofelis; Ref: Reference category; * L. infantum infection: confirmed by DNA sequencing } \\
\text { following confirmatory qPCR and/or positive ELISA. }\end{array}$} \\
\hline
\end{tabular}

Univariate analysis (Tables 1 and 2) revealed significant associations $(p \leq 0.05)$ between $T$. gondii seropositivity and the followings factors: never vaccinated, no application of ectoparasitic prevention, seropositivity for FIV, and positive Hepatozoon spp. PCR. Additionally, a trend toward significance $(p<0.2)$ for $T$. gondii seropositive was noted for cats 
that were non-pedigree, had outdoor access, lived in a rural area, were PCR-positive for CMhm and PCR-positive for at least one feline vector borne pathogen (FVBP).

A multivariate logistic regression model (Table 3) was constructed and yielded significant associations $(p \leq 0.05)$ for T. gondii seropositive that included FIV seropositivity (odds ratio $(\mathrm{OR})=5.0,95 \%$ confidence interval $(\mathrm{CI}): 2.0-13.0, p=0.001$ ) and never being vaccinated $(\mathrm{OR}=2.5,95 \% \mathrm{CI}: 1.2-5.7, p=0.019)$.

Table 3. Multivariate logistic regression models regarding Toxoplasma gondii seropositivity in cats from Cyprus.

\begin{tabular}{ccc}
\hline & Odds Ratio (95\% CI) & $p$-Value \\
\hline FIV antibody & & \\
\hline Positive & $5.0(2.0-13.0)$ & $\mathbf{0 . 0 0 1}$ \\
\hline Negative & Ref. & \\
\hline Vaccination status & & $\mathbf{0 . 0 1 9}$ \\
\hline Never vaccinated & $2.6(1.2-5.7)$ & \\
\hline Vaccinated & Ref. & \\
\hline
\end{tabular}

CI: Confidence interval; Ref: Reference category; FIV: feline immunodeficiency virus; Significant $p$-values $\leq 0.05$ are shown in bold.

\section{Discussion}

Toxoplasma gondii is a prevalent parasite and toxoplasmosis affects a wide range of animals, both wild and domestic. Clinical toxoplasmosis in cats is rare; however it can occur in congenital infections that can be fatal, or postnatal infections in immunosuppressed cats, mainly involving the central nervous system and, less often, other organs, such as the lungs and eyes [21]. Farmed small ruminants, i.e., sheep and goats, are susceptible species, where toxoplasmosis is one the most important and prevalent causes of abortion, greatly affecting production and causing economic losses [22]. In Cyprus, the seroprevalence of T. gondii infection in small ruminants (sheep and goats) was found to be $40.1 \%$ in a recent survey [19].

Human toxoplasmosis in immunocompetent individuals usually remains asymptomatic, but rarely, it may cause a flu-like syndrome with fever, lymphadenopathy, hepatosplenomegaly and ocular lesions [23]. The most important implications of human toxoplasmosis are in immunosuppressed individuals, who can develop severe and even fatal disease, and in congenital infections that, depending on the gestational age at infection, can have a wide range of outcomes, from abortion to birth of asymptomatic infected infants [24,25]. In Cyprus, T. gondii seroprevalence in humans has been investigated in two groups of females: 16-18-year-old girls and pregnant women, showing prevalences of $6.5 \%$ and $18.0 \%$, respectively [19]. A system for the epidemiological surveillance of symptomatic toxoplasmosis, both congenital or post-natal, has been employed in Cyprus since 2004 [26]. Nevertheless, there is evidence that such cases are still underreported [19].

In an epidemiological survey that took place in the early 2010s in several areas in Cyprus, Paphos displayed the highest seroprevalence in girls and women compared to the other districts of Cyprus [19]. However, in our study's results, the seroprevalence in cats in Paphos was not higher than in other areas. This is not necessarily a contradictory observation, as the main mode of human infection by T. gondii is via consumption of raw or undercooked infected meat, or via ingestion of sporulated oocysts found on unwashed fruits and vegetables. Both ways of transmission involve foodstuffs that are moved from other areas of Cyprus, and are not related to contact with local contaminated soil [27]. In our present study, all districts of Cyprus displayed similar rates of feline infection, which is not surprising as there are no boundaries on the island that could isolate cat populations and, similarly, the intermediate hosts playing a key role in feline infection (rodents and birds) are abundant in all districts, and have been found to have a high percentage of up to $27.9 \%$ of seropositivity [18]. 
Cats are abundant in Cyprus, both as owned pets and as strays and, according to recent estimations, their population has reached 1.5 million [28]. Surveys investigating infectious and parasitic diseases of Cyprus cats are scant $[15,17]$. The current study is the first serological investigation of T. gondii infection in cats in Cyprus. Such surveys are needed to monitor the occurrence of this important pathogen in a given region and to predict the risk of infection in farm animals and humans [14].

In Europe, several T. gondii seroprevalence studies in feline populations have been conducted over the last decade [5]. The result of the present survey shows that the infection rate in Cyprus (32.3\%) is consistent with the recently reported prevalences in most areas in Europe, even though in some countries, such as Poland, France, Estonia and Albania, percentages of over $60.0 \%$ have been recorded [29-33]. During the last decade, the highest percentage of seropositive animals $(84.7 \%$ ) was recorded in the island of Majorca, in feral cats [34]. In areas of continental Spain, T. gondii seroprevalence was recorded as $36.9 \%$ in stray, $33.3 \%$ in farm and $25.5 \%$ in pet animals [35]. Interestingly, the lowest $T$. gondii seroprevalence in Europe was found in a breeding Persian cat colony, at 10.0\% [36]. The latter indicates that cats living in a family household, without outdoor access, can still be infected, most probably by feeding of raw meat and less probably by ingesting infective oocysts that are mechanically transported in the house on the shoes or on arthropods [13]. Indeed, T. gondii is adapted to a tissue cyst-oral route of transmission in cats, as it has been shown that one tissue cyst is a competent infective dose, while 100 or more sporulated oocysts may be required to establish infection in a cat [37]. Accordingly, less than $50 \%$ of cats acquire a patent infection after ingesting oocysts, while almost all eliminate oocysts after tissue cyst consumption [22]. Similar to the lifestyle types evidenced as risk factors for T. gondii in previous surveys, the results of the present study show that cats with a likely lower veterinary care profile i.e., never vaccinated and without ectoparasite prevention, were significantly more likely to be seropositive. Furthermore, cats that had outdoor access, and cats that lived in a rural area, had a trend towards a statistically significant higher infection percentage than the cats with an indoor lifestyle or living in urban environment, respectively. This finding could be associated with the opportunity of a cat to prey on intermediate hosts (e.g., rodent or bird), which may occur more frequently for cats with outdoor access or living in rural areas. For these obvious reasons, outdoor access and living in peri-urban areas were also identified as risk factors for $T$. gondii infection in previous studies [13,35,38-41]. Accordingly, the association found in the present study between Hepatozoon spp. and T. gondii infection, using univariate analysis, is most likely related to the inadequate veterinary care and lack of ectoparasites prevention that usually occurs in cats with the above-mentioned lifestyle characteristics.

Age was not identified as a risk factor in the present study, despite there being a trend towards a significant association with seropositivity for cats more than one year of age compared to cats of one year of age or younger. Seroconversion in cats takes place 3-4 weeks post-infection and seropositivity lasts practically for all their lives, making age association an expected feature due to the accumulation of infection in older cats [31,42]. However, the fact that most cats are infected young, on their early hunting expeditions, abolish age-dependence after the first months of the animals' life. Similarly, sex was also not associated with $T$. gondii seroprevalence in the present survey, as was also the case in several previous studies [42-44]. However, sex has been related with infection risk in some reports, with females found to be more prevalently infected than males [38], or with males being infected at a higher rate, but only when the studied cats had outdoor access [45]. Nevertheless, sex has an unclear relation to T. gondii infection prevalence.

In the present study, a significant association between FIV infection and seropositivity to T. gondi was found in the final multivariate logistic regression model. It has been suggested that immunosuppression associated with feline leukaemia virus (FeLV) and FIV infection may predispose cats to toxoplasmosis [46-48]. However, in some surveys, no association with these two retroviral infections has been documented $[46,49]$. The results of the present study are in accordance with most epizootiological surveys, which have evidenced 
that it is mainly FIV, rather that FeLV, that is correlated with Toxoplasma infection $[41,42,50]$. The immunodeficiency caused by FIV infection is most likely the underlying cause of cats enhanced susceptibility to Toxoplasma infection and for the antigenaemia and increased antibody synthesis resulted by the proliferation of cyst bradyzoites in already infected cats, facilitated by the impact of the viral infection [51,52].

CMhm infection showed a trend toward significance for T. gondii seropositivity but did not yield a significant association under multivariate logistic regression analysis. In accordance with the present results, in a survey in Albania, a higher percentage of cats were simultaneously infected with haemoplasmas and T.gondii than with haemoplasmas only, but the association was non-significant [31]. A possible association between common haemoplasmas infecting cats and susceptibility to T. gondii infection is worth further investigation in the future.

Toxoplasma gondii represents an important agent in terms of disease and of zoonotic impact and economic implications in animal production. For these reasons, there is great merit in monitoring its epizootiological/epidemiological trends. In Cyprus, further studies in more animal species and an investigation of the factors involved in human infection are warranted to form a clearer image of infection prevalence and risk factors. Finally, raising public awareness of the ways to prevent $T$. gondii infection of animals and humans is pivotal in terms of the One Health concept.

Supplementary Materials: The following are available online at https:/ /www.mdpi.com/article/10.3 390/pathogens10070882/s1, The Supplementary File 1 has all the datasets supporting the findings of this study.

Author Contributions: C.A. and S.T. conceived the study, and all participated in its design and coordinated the experiments. C.A. and C.Y. designed and performed the collection of the samples and records. A.D. performed the serology sample examination. Statistical analysis was performed by C.A. A.D. drafted part of the first manuscript, supervised the subsequent versions until the submission. C.A. drafted part of the first manuscript, edited subsequent versions. All authors have read and agreed to the published version of the manuscript.

Funding: C.A. is a Wellcome Trust Clinical Ph.D. Fellow (203919/Z/16/Z) and the open access publication fees have been sponsored by Wellcome Trust.

Institutional Review Board Statement: The study was conducted according to the guidelines of the Declaration of Helsinki and approved by the University of Bristol's Animal Welfare and Ethical Review Board (Veterinary Investigation number: 14/037). All procedures were performed in accordance of the Cypriot legislation [The Dogs LAW, N. 184 (I)/2002].

Informed Consent Statement: Written informed consent has been obtained from cat's owners or animal shelter managers.

Data Availability Statement: The Supplementary File 1 has all the datasets supporting the findings of this study.

Conflicts of Interest: The authors declare no conflict of interest.

\section{References}

1. Dubey, J.P. Toxoplamosis of Humans and Animals, 2nd ed.; CRC Press: Beltsville, MD, USA, 2010.

2. Innes, E.A. A brief history and overview of Toxoplasma gondii. Zoonoses Public Health 2010, 57, 1-7. [CrossRef] [PubMed]

3. Tenter, A.M.; Heckeroth, A.R.; Weiss, L.M. Toxoplasma gondii: From animals to humans. Int. J. Parasitol. 2000, 30, 1217-1258. [CrossRef]

4. Dubey, J.P.; Verma, S.K.; Ferreira, L.R.; Oliveira, S.; Cassinelli, A.B.; Ying, Y.; Kwok, O.C.; Tuo, W.; Chiesa, O.A.; Jones, J.L. Detection and survival of Toxoplasma gondii in milk and cheese from experimentally infected goats. J. Food Prot. 2014, 77, 1747-1753. [CrossRef] [PubMed]

5. Dubey, J.P.; Cerqueira-Cézar, C.K.; Murata, F.H.A.; Kwok, O.C.H.; Yang, Y.R.; Su, C. All about toxoplasmosis in cats: The last decade. Vet. Parasitol. 2020, 283, 109145. [CrossRef]

6. Reid, A.J.; Vermont, S.J.; Cotton, J.A.; Harris, D.; Hill-Cawthorne, G.A.; Könen-Waisman, S.; Latham, S.M.; Mourier, T.; Norton, R.; Quail, M.A.; et al. Comparative genomics of the apicomplexan parasites Toxoplasma gondii and Neospora caninum: Coccidia differing in host range and transmission strategy. PLoS Pathog. 2012, 8, e1002567. [CrossRef] 
7. CDC. Available online: https://www.cdc.gov/parasites/toxoplasmosis/index.html (accessed on 10 April 2021).

8. Dubey, J.P.; Jones, J.L. Toxoplasma gondii infection in humans and animals in the United States. Int. J. Parasitol. 2008, 38, 1257-1278. [CrossRef]

9. Elmore, S.A.; Jones, J.L.; Conrad, P.A.; Patton, S.; Lindsay, D.S.; Dubey, J.P. Toxoplasma gondii: Epidemiology, feline clinical aspects, and prevention. Trends Parasitol. 2010, 26, 190-196. [CrossRef]

10. Hill, D.; Dubey, J.P. Toxoplasma gondii: Transmission, diagnosis and prevention. Clin. Microbiol. Infect. 2002, 8, 634-640. [CrossRef] [PubMed]

11. Dubey, J.P. Toxoplasmosis-A waterborne zoonosis. Vet. Parasitol. 2004, 126, 57-72. [CrossRef]

12. Dubey, J.P. Duration of immunity to shedding of Toxoplasma gondii oocysts by cats. J. Parasitol. 1995, 81, 410-415. [CrossRef]

13. Schreiber, N.; Basso, W.; Riond, B.; Willi, B.; Torgerson, P.R.; Deplazes, P. Antibody kinetics and exposure to Toxoplasma gondii in cats: A seroepidemiological study. Int. J. Parasitol. 2021, 51, 291-299. [CrossRef]

14. Bawm, S.; Phyu, A.Z.; Chel, H.M.; Htun, L.L.; Nakao, R.; Katakura, K. Seroprevalence of Toxoplasma gondii in household cats in Myanmar and molecular identification of parasites using feline faecal oocysts. Food Waterborne Parasitol. 2020, 20 , e00094. [CrossRef]

15. Diakou, A.; Sofroniou, D.; Di Cesare, A.; Kokkinos, P.; Traversa, D. Occurrence and zoonotic potential of endoparasites in cats of Cyprus and a new distribution area for Troglostrongylus brevior. Parasitol. Res. 2017, 116, 3429-3435. [CrossRef]

16. Attipa, C.; Neofytou, K.; Yiapanis, C.; Martínez-Orellana, P.; Baneth, G.; Nachum-Biala, Y.; Brooks-Brownlie, H.; Solano-Gallego, L.; Tasker, S. Follow-up monitoring in a cat with leishmaniosis and coinfections with Hepatozoon felis and 'Candidatus Mycoplasma haemominutum'. J. Feline Med. Surg. Open Rep. 2017, 3, 2055116917740454.

17. Attipa, C.; Papasouliotis, K.; Solano-Gallego, L.; Baneth, G.; Nachum-Biala, Y.; Sarvani, E.; Knowles, T.G.; Mengi, S.; Morris, D.; Helps, C.; et al. Prevalence study and risk factor analysis of selected bacterial, protozoal and viral, including vector-borne, pathogens in cats from Cyprus. Parasites Vectors 2017, 10, 130. [CrossRef] [PubMed]

18. Psaroulaki, A.; Antoniou, M.; Toumazos, P.; Mazeris, A.; Ioannou, I.; Chochlakis, D.; Christophi, N.; Loukaides, P.; Patsias, A.; Moschandrea, I.; et al. Rats as indicators of the presence and dispersal of six zoonotic microbial agents in Cyprus, an island ecosystem: A seroepidemiological study. Trans. R Soc. Trop. Med. Hyg. 2010, 104, 733-739. [CrossRef]

19. Liassides, M.; Christodoulou, V.; Moschandreas, J.; Karagiannis, C.; Mitis, G.; Koliou, M.; Antoniou, M. Toxoplasmosis in female high school students, pregnant women and ruminants in Cyprus. Trans. R Soc. Trop. Med. Hyg. 2016, 110, 359-366. [CrossRef]

20. Parigi, M.; Poglayen, G.; Rossi, D.; Bruschi, F.; Monteleone, R.M.; Veronesi, F.; Diaferia, M.; Papa, P.; Lamin Saleh, S.M. Toxoplasmosis in Saharawi camps: Seroprevalence in cats. In Proceedings of the Societa' Italiana di Parassitologia XXVII Congresso Nazionale, Pavia, Italy, 26 June 2012.

21. Hartmann, K.; Addie, D.; Belák, S.; Boucraut-Baralon, C.; Egberink, H.; Frymus, T.; Gruffydd-Jones, T.; Hosie, M.J.; Lloret, A.; Lutz, H.; et al. Toxoplasma gondii infection in cats: ABCD guidelines on prevention and management. J. Feline Med. Surg. 2013, 15, 631-637. [CrossRef]

22. Dubey, J.P. History of the discovery of the life cycle of Toxoplasma gondii. Int. J. Parasitol. 2009, 39, 877-882. [CrossRef]

23. Halonen, S.K.; Weiss, L.M. Toxoplasmosis. Handb. Clin. Neurol. 2013, 114, 125-145. [PubMed]

24. Hampton, M.M. Congenital Toxoplasmosis: A Review. Neonatal Netw. 2015, 34, 274-278. [CrossRef]

25. Khan, K.; Khan, W. Congenital toxoplasmosis: An overview of the neurological and ocular manifestations. Parasitol. Int. 2018, 67, 715-721. [CrossRef]

26. Bénard, A.; Petersen, E.; Salamon, R.; Chêne, G.; Gilbert, R.; Salmi, L.R. Survey of European programmes for the epidemiological surveillance of congenital toxoplasmosis. Euro Surveill. 2008, 13, 18834. [CrossRef] [PubMed]

27. Kapperud, G.; Jenum, P.A.; Stray-Pedersen, B.; Melby, K.K.; Eskild, A.; Eng, J. Risk factors for Toxoplasma gondii infection in pregnancy. Results of a prospective case-control study in Norway. Am. J. Epidemiol. 1996, 144, 405-412. [CrossRef] [PubMed]

28. Tovima. Available online: https:/ /www.tovima.gr/2018/03/14/society/gemise-me-gates-i-kypros/ (accessed on 6 April 2021).

29. Michalski, M.M.; Platt-Samoraj, A.; Mikulska-Skupień, E. Toxoplasma gondii antibodies in domestic cats in Olsztyn urban area, Poland. Wiad. Parazytol. 2010, 56, 277-279.

30. Afonso, E.; Germain, E.; Poulle, M.-L.; Ruette, S.; Devillard, S.; Say, L.; Villena, I.; Aubert, D.; Gilot-Fromont, E. Environmental determinants of spatial and temporal variations in the transmission of Toxoplasma gondii in its definitive hosts. Int. J. Parasitol. Parasites Wildl. 2013, 2, 278-285. [CrossRef]

31. Silaghi, C.; Knaus, M.; Rapti, D.; Kusi, I.; Shukullari, E.; Hamel, D.; Pfister, K.; Rehbein, S. Survey of Toxoplasma gondii and Neospora caninum, haemotropic mycoplasmas and other arthropod-borne pathogens in cats from Albania. Parasites Vectors 2014, 7, 62. [CrossRef]

32. Must, K.; Lassen, B.; Jokelainen, P. Seroprevalence of and Risk Factors for Toxoplasma gondii Infection in Cats in Estonia. Vector Borne Zoonotic Dis. 2015, 15, 597-601. [CrossRef]

33. Sroka, J.; Karamon, J.; Dutkiewicz, J.; Wójcik Fatla, A.; Zając, V.; Cencek, T. Prevalence of Toxoplasma gondii infection in cats in southwestern Poland. Ann. Agric. Environ. Med. 2018, 25, 576-580. [CrossRef]

34. Millán, J.; Cabezón, O.; Pabón, M.; Dubey, J.P.; Almería, S. Seroprevalence of Toxoplasma gondii and Neospora caninum in feral cats (Felis silvestris catus) in Majorca, Balearic Islands, Spain. Vet. Parasitol. 2009, 165, 323-326. [CrossRef] [PubMed]

35. Miró, G.; Montoya, A.; Jiménez, S.; Frisuelos, C.; Mateo, M.; Fuentes, I. Prevalence of antibodies to Toxoplasma gondii and intestinal parasites in stray, farm and household cats in Spain. Vet. Parasitol. 2004, 126, 249-255. [CrossRef] [PubMed] 
36. Miró, G.; Hernández, L.; Montoya, A.; Arranz-Solís, D.; Dado, D.; Rojo-Montejo, S.; Mendoza-Ibarra, J.A.; Ortega-Mora, L.M.; Pedraza-Díaz, S. First description of naturally acquired Tritrichomonas foetus infection in a Persian cattery in Spain. Parasitol. Res. 2011, 109, 1151-1154. [CrossRef]

37. Dubey, J.P. Infectivity and pathogenicity of Toxoplasma gondii oocysts for cats. J. Parasitol. 1996, 82, 957-961. [CrossRef] [PubMed]

38. Hornok, S.; Edelhofer, R.; Joachim, A.; Farkas, R.; Berta, K.; Répási, A.; Lakatos, B. Seroprevalence of Toxoplasma gondii and Neospora caninum infection of cats in Hungary. Acta Vet. Hung. 2008, 56, 81-88. [CrossRef] [PubMed]

39. Lopes, A.P.; Cardoso, L.; Rodrigues, M. Serological survey of Toxoplasma gondii infection in domestic cats from northeastern Portugal. Vet. Parasitol. 2008, 155, 184-189. [CrossRef] [PubMed]

40. Opsteegh, M.; Haveman, R.; Swart, A.N.; Mensink-Beerepoot, M.E.; Hofhuis, A.; Langelaar, M.F.; van der Giessen, J.W. Seroprevalence and risk factors for Toxoplasma gondii infection in domestic cats in The Netherlands. Prev Vet. Med. 2012, 104, 317-326. [CrossRef]

41. Munhoz, A.D.; Hage, S.B.; Cruz, R.D.S.; Calazans, A.P.F.; Silva, F.L.; Albuquerque, G.R.; Lacerda, L.C. Toxoplasmosis in cats in northeastern Brazil: Frequency, associated factors and coinfection with Neospora caninum, feline immunodeficiency virus and feline leukemia virus. Vet. Parasitol. Reg. Stud. Rep. 2017, 8, 35-38. [CrossRef]

42. Akhtardanesh, B.; Ziaali, N.; Sharifi, H.; Rezaei, S. Feline immunodeficiency virus, feline leukemia virus and Toxoplasma gondii in stray and household cats in Kerman-Iran: Seroprevalence and correlation with clinical and laboratory findings. Res. Vet. Sci 2010, 89, 306-310. [CrossRef]

43. Maruyama, S.; Kabeya, H.; Nakao, R.; Tanaka, S.; Sakai, T.; Xuan, X.; Katsube, Y.; Mikami, T. Seroprevalence of Bartonella henselae, Toxoplasma gondii, FIV and FeLV infections in domestic cats in Japan. Microbiol. Immunol. 2003, 47, 147-153. [CrossRef]

44. Sharif, M.; Daryani, A.; Nasrolahei, M.; Ziapour, S.P. Prevalence of Toxoplasma gondii antibodies in stray cats in Sari, Northern Iran. Trop. Anim. Health Prod. 2009, 41, 183-187. [CrossRef]

45. Sukhumavasi, W.; Bellosa, M.L.; Lucio-Forster, A.; Liotta, J.L.; Lee, A.C.; Pornmingmas, P.; Chungpivat, S.; Mohammed, H.O.; Lorentzen, L.; Dubey, J.P.; et al. Serological survey of Toxoplasma gondii, Dirofilaria immitis, Feline Immunodeficiency Virus (FIV) and Feline Leukemia Virus (FeLV) infections in pet cats in Bangkok and vicinities, Thailand. Vet. Parasitol. 2012, 188, 25-30. [CrossRef]

46. Svobodová, V.; Knotek, Z.; Svoboda, M. Prevalence of IgG and IgM antibodies specific to Toxoplasma gondii in cats. Vet. Parasitol. 1998, 80, 173-176. [CrossRef]

47. Witt, C.J.; Moench, T.R.; Gittelsohn, A.M.; Bishop, B.D.; Childs, J.E. Epidemiologic observations on feline immunodeficiency virus and Toxoplasma gondii coinfection in cats in Baltimore, Md. J. Am. Vet. Med. Assoc. 1989, 194, 229-233. [PubMed]

48. Pedersen, N.C.; Torten, M.; Rideout, B.; Sparger, E.; Tonachini, T.; Luciw, P.A.; Ackley, C.; Levy, N.; Yamamoto, J. Feline leukemia virus infection as a potentiating cofactor for the primary and secondary stages of experimentally induced feline immunodeficiency virus infection. J. Virol. 1990, 64, 598-606. [CrossRef] [PubMed]

49. Spada, E.; Proverbio, D.; della Pepa, A.; Perego, R.; Baggiani, L.; DeGiorgi, G.B.; Domenichini, G.; Ferro, E.; Cremonesi, F. Seroprevalence of feline immunodeficiency virus, feline leukaemia virus and Toxoplasma gondii in stray cat colonies in northern Italy and correlation with clinical and laboratory data. J. Feline Med. Surg. 2012, 14, 369-377. [CrossRef] [PubMed]

50. Dorny, P.; Speybroeck, N.; Verstraete, S.; Baeke, M.; De Becker, A.; Berkvens, D.; Vercruysse, J. Serological survey of Toxoplasma gondii, feline immunodeficiency virus and feline leukaemia virus in urban stray cats in Belgium. Vet. Rec. 2002, 151, 626-629. [CrossRef] [PubMed]

51. Lappin, M.R.; Gasper, P.W.; Rose, B.J.; Powell, C.C. Effect of primary phase feline immunodeficiency virus infection on cats with chronic toxoplasmosis. Vet. Immunol. Immunopathol. 1992, 35, 121-131. [CrossRef]

52. Davidson, M.G.; Rottman, J.B.; English, R.V.; Lappin, M.R.; Tompkins, M.B. Feline immunodeficiency virus predisposes cats to acute generalized toxoplasmosis. Am. J. Pathol. 1993, 143, 1486-1497. 